\title{
Correction to: Natronorubrum halalkaliphilum sp. nov., a haloalkaliphilic archaeon isolated from soda lake in Inner Mongolia Autonomous Region, China
}

\author{
Qiong Xue ${ }^{1,2} \cdot$ Dahe Zhao $^{1} \mathbb{D} \cdot$ Zhenqiang Zuo $^{1,2} \cdot$ Jian Zhou $^{1} \cdot$ Hua Xiang ${ }^{1,2}$
}

Published online: 14 December 2021

(c) Springer-Verlag GmbH Germany, part of Springer Nature 2021

\section{Correction to: \\ Archives of Microbiology (2021) 203:2335-2342 \\ https://doi.org/10.1007/s00203-021-02207-8}

In the original article, the accession number of type strain is incorrect at JCM. The correct accession number is "JCM $34235 "$.

Publisher's Note Springer Nature remains neutral with regard to jurisdictional claims in published maps and institutional affiliations.

The original article can be found online at https://doi.org/10.1007/ s00203-021-02207-8.

Dahe Zhao

zhaodh@im.ac.cn

$\triangle$ Hua Xiang

xiangh@im.ac.cn

1 State Key Laboratory of Microbial Resources, Institute of Microbiology, Chinese Academy of Sciences, Beijing 100101, China

2 University of Chinese Academy of Sciences, Beijing 100049, China 